El primer curso. Lingüistica general de Ferdinand de Saussure, Louis Caille y Albert Riedlinger

\title{
Mejía, C., Jaramillo, D. \& Pérez, A. (2019). El primer curso. Lingüística general de Ferdinand de Saussure, Louis Caille y Albert Riedlinger (Colección Aposemas). Medellín: Editorial Semsa, 423 pp.
}

\author{
Miguel Orlando Betancourt Cardona \\ Universidad de Antioquia (Colombia) \\ miguel.betancourt@udea.edu.co
}

\begin{abstract}
Recibida: 03/08/2020 - Aprobada: 18/11/2020 - Publicada: 15/04/2021
DOI: doi.org/10.17533/udea.lyl.n79a31
\end{abstract}

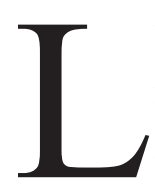

ibro ambicioso y seductor, dotado de una bella presentación y una cobertura de lujo, con letras e ilustraciones que permiten una placentera lectura, el cual ofrece una traducción reconstructiva del primer curso de Lingüística General de Ferdinand de Saussure. En la introducción presenta los honores a la obra de dicho autor, subrayando que es gracias a sus estudiantes «que el discurso del profesor todavía se puede escuchar hoy en día, más de un siglo después» (p. viI).

Este libro refleja, otorgándole actualidad y vigencia, la transmisión oral del pensamiento lingüístico saussureano, como una resultante de un laborioso trabajo de edición. Dentro del mismo se puede develar una reconstrucción de fragmentos de notas que se entretejen en unas cien páginas de traducción que adoptan el carácter de una traducción reconstructiva, concepto que maravillosamente propone esta obra.

El trabajo realizado por los autores plasma, en el libro, dos perspectivas muy interesantes: por un lado, evoca las lecciones del primer curso de Saussure al remitirse al salón de clase de Saussure en 1907 para recrear sus lecciones. Por el otro, permite disfrutar de una vivencia de traducción; pues se trata de una edición semiológica de los apuntes tomados en clase por sus alumnos Louis Caille y Albert Riedlinger, y que se constituyen en notas y a la vez fuentes primarias de este curso. Leyendo el libro se puede escuchar a Saussure en francés y en español «Hasta hoy, ningún curso completo de Saussure había sido traducido al español» (p. XVI). ¿Será que es el pensamiento de Saussure permeado por la comprensión de sus estudiantes?

Lo seductor de este libro es que saca a la luz el trabajo teórico y metodológico de Saussure y al mismo tiempo revela su valor lingüístico, científico y cultural. Es atrayente por la eficacia para dar a comprender el organismo gramatical de las lenguas que el ilustre profesor suizo enseñaba; aunque como sus autores lo señalaron, él «jamás se pronunció sobre la manera adecuada de enseñar lenguas» (p. VIII). Sin embargo, el cuidadoso entretejido de estas notas deja a la vista que el discurso didáctico de Saussure «no es simple teoría ilustrada con ejemplos concretos, sino el análisis de problemas particulares [...] cuya solución lleva a descubrir» (p. x). ¿Será, entonces, un aporte capital de esta obra el develamiento del método didáctico de Saussure?

Lo ambicioso de este libro es que plantea una nueva posibilidad en traducción y una nueva discusión en 
El primer curso. Lingüística general de Ferdinand de Saussure, Louis Caille y Albert Riedlinger

traductología. El entretejido en filigrana que une trozos de conocimiento a la manera de una colcha de retazos, para dar sentido a un texto como una reconstrucción del discurso científico y didáctico impartido durante el primer curso de Saussure es la razón misma de ser de este libro. ¿Constituye entonces esta obra el primer ejemplo de esta forma de traducción? Podría asegurarse que; efectivamente, es pionero como una vivencia de la traducción en este campo y, por lo tanto, el primero en lanzar la discusión implícita en el libro del concepto de traducción reconstructiva.

Dos frentes entonces constituyen la empresa de este ilustrativo libro que son realmente dos contribuciones capitales por lo menos en el campo de las humanidades: primero, dar a conocer la gran riqueza científica del primer curso de Saussure mediante una sonoridad transcultural, pues los sonidos del español y del francés se complementan en la posibilidad otorgada por la presentación bilingüe, en todo caso, mínimamente para el lector francoparlante.

Segundo, presentar una forma de traducción diferente. Se trata de la traducción de «textos singulares» que fueron producto de los apuntes tomados por los estudiantes durante las clases y que como tal tienen características particulares: contienen, por ejemplo, «frases elípticas a veces mal escritas o sin terminar y llenas de abreviaciones» (p. XVI). En algunos casos, estos textos «son más elaborados» (p. XVI), pero «escuetos y condensados y no presentan muchos enlaces sintácticos explícitos» (p. XVI). Esta realidad solicitó — según los autores — el ejercicio de la lectura meticulosa que escudriña para comprender y luego exigió el análisis de estas estructuras sedimentadas para entender su devenir histórico, como diría Derrida (1992), en lo solemne de la restauración, [en] esa construcción y reconstrucción que conserva. Ante esta realidad, Mejía, Jaramillo y Pérez (2019) se dieron a la tarea de analizar las estructuras sedimentadas que forman el elemento discursivo del primer curso de Saussure, de recontextualizar las cosas. Dicho esto, la traducción presentada en el libro hace posible que el lector converse con Saussure y escuche sus conversaciones con sus estudiantes. Así, se está, pues, ante «la letra del [los] estudiante[s] y la expresión oral del profesor» (p. XVII) que suenan en el original y resuenan en la traducción como una práctica de traducción análoga a la reconstrucción lingüística. En todo caso, como lo consideró Basalamah (1997), la libertad de traducir tan sólo es la afirmación de la libertad de transformarse mediante el contacto con los otros y con la puesta en obra de un diálogo interno, de un conocimiento, de un perpetuo viaje de ida y vuelta; así mismo, con la imperiosa perspectiva de traducir al otro en un deseo de mediación hacia la universalidad.

Antes de presentarse el curso de lingüística general impartido por el profesor Ferdinand de Saussure (19061907), el libro presenta el aparato crítico (p. XIII), donde realiza una explicación detallada de lo que representa la construcción de una transmisión oral por escrito. Luego, en otro aparte (p. XXXIX), se comparten detalles sobre la edición de los manuscritos. En este punto, se indica claramente la transcripción de los apuntes de los alumnos, los criterios de transcripción, las transcripciones de los apuntes en taquigrafía y el desciframiento sintagmático. En un tercer aparte (p. LXXII), se presenta la traducción de un «acto de hablar». En esta instancia, se sitúa la época del discurso, el estilo del hablar, la sintaxis, el tránsito del discurso saussureano desde la lengua francesa hacia el encuentro con la lengua española y el encuentro de la oralidad con la escritura; en resumen, se relacionan los 
El primer curso. Lingüistica general de Ferdinand de Saussure, Louis Caille y Albert Riedlinger

discursos involucrados en los textos que finalmente conformarían el primer curso de Saussure.

Se trata de un bonito libro, novedoso en su propuesta, de interés para los traductores, los lingüistas y los estudiosos de la pedagogía y la didáctica de la enseñanza de las lenguas y de la traducción. Quedaría por interrogarse si traer al presente a Saussure ¿no sería como traer al presente «el momento en el que las ciencias del lenguaje, la referencia a la lingüística y el todo es lenguaje eran dominantes» (Derrida 1992, p. 4305612). ¿Y la próxima traducción? Queda abierto el debate.

\section{Referencias bibliográficas}

1. Basalamah, S. (2009). Le Droit de traduire : Une politique culturelle pour la mondialisation. Ottawa: Les Presses de 1'Université d'Ottawa | University of Ottawa Press. http://books.openedition.org/uop/994

2. Derrida, J. (12 de octubre de 2004). Qu'est-ce que la déconstruction ? Le Monde. (Entrevista inédita del 30 de junio de 1992). https://www.lemonde.fr/archives/article/2004/10/12/p-1930-2004-p-p-jacques-derrida-p-p-quest-ce-que-la-deconstruction-p_4305612_1819218.html

3. Mejía, C., Jaramillo, D. \& Pérez A. (2019). El primer curso. Lingüística general de Ferdinand de Saussure, Louis Caille y Albert Riedlinger. (Colección Aposemas). Medellín: Editorial Semsa. 